\title{
Linking Technological System Architecture and Purchasing Categories
}

\author{
Elina Karttunen \\ School of Business and Management \\ Lappeenranta University of Technology \\ elina.karttunen@1ut.fi
}

\author{
Janne Nerg \\ School of Energy Systems \\ Lappeenranta University of Technology \\ janne.nerg@lut.fi
}

\begin{abstract}
Though the link between technological system architectures and buyer-supplier relationships has been actively studied, no comprehensive framework connecting system structures and component purchasing categories exists. We examine the technological dependency structures of such systems by adopting the buyer's viewpoint as system assembler and integrator. We articulate how system dependencies relate to switching costs and needs for investments and technological expertise in buyer-supplier relationships. By examining the extents and directions of indirect and direct dependencies at the technological systems level, we are able to identify the purchasing category to which each component is most likely to belong. We demonstrate our theoretical framework using an empirical example of a technological system from the energy industry.
\end{abstract}

\section{Introduction}

Successful organizations effectively manage, access, and use both internal and external resources. Supplier relationships are key to external resources, and when relationship quality is high, both buyer and supplier benefit from increased overall competitiveness. Organizations are open systems that depend on events in the external environment [1]; that is, they do not act independently. Relationships range from close and intense to distant. But how are the linkages between resources and buyer-supplier relationships studied? Traditionally, researchers have addressed this question by defining components' modularity levels and examining the related buyer-supplier relationships. However, modularity alone is insufficient to explain buyer-supplier relationship characteristics. Previous approaches have found both conflicting and supporting results concerning the effects of product architectures on inter-organizational relationships [2][3][4]. However, the ways in which technological system architectures and inter-organizational relationships interact remain unknown[5].

The present study structures supplier-buyer relationships using the purchasing portfolio approach [6]. Purchasing portfolio categorization involves statements about buyer-supplier relationship characteristics, even when this relationship is connected to a purchased component. Supply risk and profit impact are the classifying dimensions [7]. Portfolio approaches have often been criticized for their lack of patterns for operationalizing dimensions and of fine-grained or widely tested criteria to assign items like components and products to categories [7][8]. In addition, product interdependencies are not monitored [9]. Researchers and practitioners leverage nebulous concepts like supply risk and profit impact, even when these concepts are defined by subjective decision making rather than operationalized measures [10][9]. Systems' technological structures are neglected in purchasing portfolio research (with a few exceptions [9][11]), though they are discussed elsewhere in supply chain literature. However, both the product purchased and its technology have been shown to significantly impact the buyer-supplier relationship [12].

In this paper, we develop new measures to allocate components to purchasing categories by leveraging systems' indirect and direct technological dependencies. The broader question concerning the link between system architectures and buyer-supplier relationships is narrowed to the purchasing context. We use purchasing portfolio categories [6][13] as anchors for our theoretical framework development. In addition, we limit the buyer's role to that of an assembler and system integrator that sources components from suppliers.

In this research, switching costs, buyer/supplier investments, and the need for technological expertise are understood as dependence dimensions that influence the buyer-supplier relationship [14]. We use indirect and direct technological dependencies to characterize how systems' technological structures affect switching costs, buyer/supplier investments, the need for technological expertise and, ultimately, the buyer-supplier relationship. We leverage Kraljic's matrix of purchasing categories, which already includes switching costs, investments, and the need for technological expertise [14][13]. Our research objective is to connect system architectures and buyer-supplier relationships in the purchasing context. Thus, we propose a theoretical framework that links system architectures with purchasing portfolio categories from the buyer's perspective. Our theory contributes to the strategic 
purchasing literature on the characteristics of purchasing categories and buyer-seller dependencies.

Assessments of purchasing portfolio component categories have traditionally been subjective; however, this paper offers system architecture-based metrics with direct practical benefits for purchasing professionals. We leverage objective measures to analyze component dependencies in technological systems [2], [5], allowing managers to better manage dependencies using our component-categorizing framework. We demonstrate the use of these metrics and the framework through the hypothetical example of a technological system from the energy industry.

\section{Supply chain dependency patterns}

\subsection{Dependency patterns in supply chains}

In this research, firms are seen as open systems that depend on events in their external environments [1]. A firm does not control all the resources necessary to operate independently; thus, it must interact with its environment to survive [1]. Hence, firms are constrained by networks of interdependencies with other organizations [15]. Dependency patterns form situations in which continuous success is uncertain, especially when a firm does not know which actors' actions are interdependent [15]. These patterns affect interorganizational power, which influences firms' behaviors [15].

Three main factors affect buyer-supplier dependence: resource importance, resource alternatives, and buyer's freedom in deciding resource-related issues [16]. Activities can be similar across supply chains, creating pooling interdependencies among firms [17]. We expect a buyer's authority over a resource to be insignificant when pooling dependencies are high. When separate supply chains leverage the same resource, the resource supplier can reach economies of scale by fitting the resource into different production contexts. This may cause reciprocal supply chain interdependencies, such that firms from different chains interact to adjust resources and separate production contexts [17]. Our theory leverages these concepts of pooling and reciprocal dependency, since they may help clarify when a buyer is more or less likely to have authority over resources.

\subsection{Purchasing portfolio approach}

Purchasing portfolios enable professional purchasers to differentiate among suppliers and choose the most effective strategy for each relation [11]. Unless the resources for building and maintaining partnerships are unlimited, different types of relationships are needed for different purchases. Partnerships are expensive to develop and maintain [12], so it is important to build numerous coordination mechanisms instead of optimizing only one level of supplier integration [18]. In this paper, we do not discuss these coordination mechanisms but how to divide the components of the purchasing portfolio categories.

Kraljic's matrix (1983) (and modifications) represents one of the most widely accepted portfolio approaches in research and practice [11][13][19]. Kraljic's original work sought to minimize supply risk and maximize firms' buying power. The matrix starts by defining supply risks and profit impact, which are two dimensions needed to build the categories. Both variables can have either "low" or "high" values, resulting in a $2 \times 2$ matrix with four quadrants: noncritical, leverage, bottleneck, and strategic [6]. These quadrants are linked to different kinds of relationships and purchasing strategies. Kraljic's second matrix addresses the strategic category, which has since been complemented by other scholars [12][9][20]. This research builds on a descriptive modification of Kraljic's matrix (shown in Figure 1). This modification focuses not on the normative patterns of what a firm should do, but on the characteristics of the buyersupplier relationship.

Strategic components are typically purchased from a single supplier and have high supply risk and profit impact. Single-source purchasing involves significant risks, which a buyer may attempt to reduce by building supplier partnerships. Strategic items do not usually lead to fierce price negotiations, but a buyer may accept higher prices if a component has a significant profit impact. If a firm seeks to reduce its long-term supplier dependence risk, it may consider backward integrating to achieve in-house production. This purchasing strategy seeks to develop long-term, close, and collaborative relations with strategic component suppliers, which can be seen as extensions of the buying firm. Total dependence is at its highest level. Since both buyer and supplier are heavily involved in the partnership, a balance of power is assumed [21]; however, supplier dominance has also been reported [14][13].

Bottleneck components have low profit impact and high supply risk. These components require continuous supply, even at additional costs. With these components, suppliers have the dominant power position, and total interdependence is moderate, but higher than in noncritical item relationships [13]. Neither buyers nor suppliers are heavily involved in the relationship if compared to strategic category. Long-term contracts, contingency planning and single sourcing purchasing practices are used to secure continuous supply. Buyers seek to adapt to their dependence, reduce the negative 
consequences of the unfavorable situation, or try to find other solutions [14].

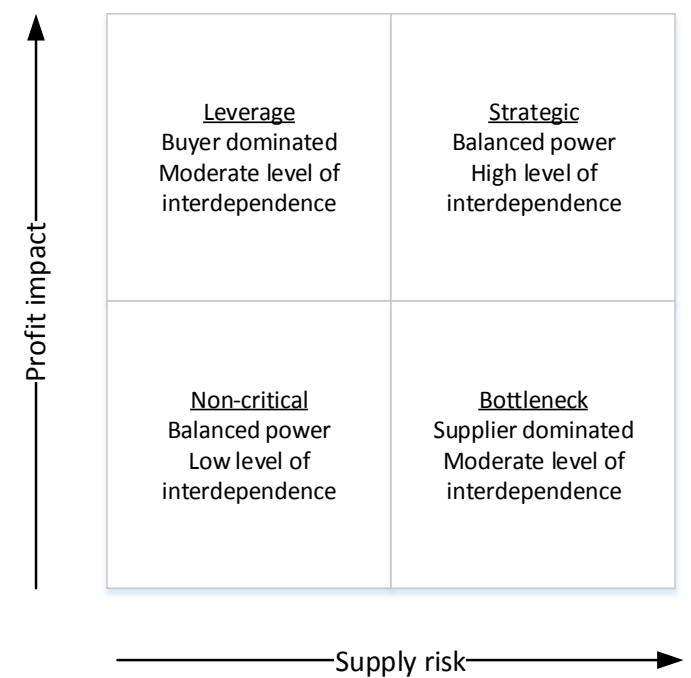

Figure 1. Categories, dimensions, and power and dependence in the purchasing portfolio matrix [14]

[13] [21]

Leverage items are associated with high profit impact but low supply risk. These items can be obtained from various suppliers, giving buyers the dominant negotiating position. There is no need for long-term supply contracts; instead, buyers arrange competitive bidding among suppliers. Leverage items contribute heavily to end product cost, so aggressively maximizing buying power may be reasonable. Suppliers' dependence is high, while buyers' dependence is low. Total interdependence is higher than for non-critical items, but lower than for strategic items [13].

Non-critical items have low profit impact and low supply risk. Buyers have many alternative suppliers, and vice versa. Neither supplier nor buyer is tied to the other; thus, there is a balance of power and a low level of interdependence [13]. Since non-critical items require significant purchasing time but represent only modest profit impact, transactions are characterized by routines and pooled purchasing requirements. Efficient processing and reductions to logistic and administrative complexity are the preferred purchasing approaches.

We argue that the matrix shown in Figure 1 does not fully capture the determinants of the buyer-supplier relationship. In particular, it does not recognize component dependencies that impact buyer-supplier relationships. In the following sections, we explore the little-researched topic of how these technological system dependencies affect the relationship.

\section{Network view of system architecture}

\subsection{System architecture and modularity}

A product architecture defines the product's functions and how these functions are mapped to physical components. Second, it specifies the component interfaces [22]. Here we use a similar concept of technological system architecture that extends the product architecture by describing an entire system. Technological dependencies between components are part of architecture as well as interfaces. We do not examine single interfaces per se, but, rather, explore technological dependencies at the system level.

Modularity in product design enables the creation of high levels of component design independence [23]. For instance, standardizing component interfaces increases modularity. These standardized interfaces define components' functional, spatial, and similar relations. Modular products help firms manage outsourcing and external manufacturing, since product modularity decreases the need for (technical) coordination. By contrast, integral architecture exists when one-to-one mapping between components and product functions is not possible and component interfaces are highly interdependent [22]. The body of modularity research relies on divisions among modular-integral product architectures. This perspective successfully captures design extremes; but it does not fully acknowledge the components' intermediate forms of interdependence. In particular, the concept of modularity does not consider the direction or amount of direct or indirect component technological dependence.

When a buyer cannot find suitable components among a supplier's existing component specifications, it may need customized components. Customization is the extent to which a product is customized for a buyer. Suppliers can serve multiple buyers through customization [24]; however, this may be challenging, since customization often requires non-transferable buyer-specific investments. The emergence of dominant designs may ease these challenges. Dominant designs help industries transition from customized, made-toorder products to standardized, mass-manufacturing systems. Dominant designs emerge when a market accepts a particular product design as the standard for the whole product category [25]. Dominant designs can be viewed as continuum, such that the majority of designs in the industry matter. Usually, dominant designs focus on core components, and individual changes cause system-level malfunctions [25].

Product modules cannot be coordinated solely through standardized interface specifications, since functional dependency structures (e.g. heat transfer, magnetic fields, etc.) that demand coordination remain. This is why modular system design is positively linked to supplier involvement: Firms must work more closely to ensure the compatibility of the modular subsystems. Significant changes in system architectures present challenges for the firms involved. Changes in system 
architectures may require shifts in industry structures, such as firm boundaries [26] [27]. If a modular architecture change to an integral architecture [26], reduced compatibility may prevent potential relations with certain suppliers in industry. System architecture decisions influence formal and informal organizational structures; thus, knowledge of system architecture improves our understanding of both technological and organizational aspects [2][27].

3.2 Buyer and supplier dependence from a technological system perspective

This chapter discusses the dimensions of buyersupplier dependence in the context of this paper. From a technological perspective, buyer dependence on suppliers has multiple dimensions, traditionally understood as switching costs. Switching costs occur when a buyer moves from one supplier to another [28]. Switching costs are often discussed as "umbrella" constructs that include other costs. We do not follow this conceptualization; instead, we use the term "switching costs" to describe a buyer's engineering costs when switching suppliers. Overall, we discuss three dimensions of a buyer's dependence on a supplier: switching costs, the buyer's need for the supplier's technological expertise, and the buyer's investments [13][28].

Supplier dependence is measured using the same dimensions as buyer dependence: switching costs, supplier investments, and the supplier's need for the buyer's technological expertise [13][28]. These are summarized in Table 1. Table 2. show both the dimensions of dependence and how these dependencies can be understood from a technological system perspective.

Switching component suppliers may require varying amounts of buyer-side engineering activities. Even small system changes may require adjustments elsewhere; however, this depends on a component's indirect and direct influences on the overall system. Thus, the extent of engineering - and, thus, a buyer's switching costs - depend on a component's cyclicality and hierarchical location in the system. A component is called an in-cycle component [5] if it is part of the cycle structure, in which a set of components form a set of interdependency paths. A decision to change an in-cycle component may force changes in other cycle components, which may force other changes until global constraints are satisfied. Long cycles with complex dependency paths lead to quality defects, greater coordination needs, cost overruns, and delays in product development [5]. These cyclical structures may trigger more changes if they are located at the top of the system hierarchy. The higher the position of a component in the hierarchy, the more system-level changes are needed to change the component. Decisions made at higher levels of the hierarchy influence lower levels [29], but decisions made at lower levels may not cause influence higher levels. From an engineering perspective, component cyclicality and hierarchy are challenges for inter-organizational teams seeking to develop fullsystem subsystems. If component cyclicality and hierarchy are not considered, substantial design problems may occur.

Table 1. Buyer dependence from a technological system perspective.

\begin{tabular}{|l|l|}
\hline Buyer dependence & $\begin{array}{l}\text { Buyer dependence from a } \\
\text { technological system perspective }\end{array}$ \\
\hline Switching costs & $\begin{array}{l}\text { Amount of engineering needed by } \\
\text { buyer when switching suppliers }\end{array}$ \\
\hline Buyer investments & $\begin{array}{l}\text { Need to adapt to supplier's } \\
\text { component (or product) through } \\
\text { specific investments }\end{array}$ \\
\hline $\begin{array}{l}\text { Need for supplier } \\
\text { technological } \\
\text { expertise }\end{array}$ & $\begin{array}{l}\text { Supplier is providing technological } \\
\text { expertise (design/manufacturing) } \\
\text { needed by buyer }\end{array}$ \\
\hline
\end{tabular}

Buyer investments (e.g. in manufacturing facilities, personnel training, and tooling) enable purchases from specific suppliers. To match these purchased components, specific processes are customized [12], which may cause changes elsewhere in the system. The final form of buyer dependence is the buyer's need for the supplier's technological expertise in areas beyond the buyer's knowledge (e.g. expertise in efficient manufacturing or technological expertise).

From a technological perspective (Table 2.), a supplier's dimensions of dependence are the same as a buyer's. Supplier switching costs are engineering costs related to a supplier switching a buyer to another. Supplier investments describe investments made for a specific buyer (e.g. investments in manufacturing facilities, dies, and personnel training) [12]. Depending on the component purchased, suppliers may need buyers' critical expertise or specialized knowledge [14]. Buyers can provide component specifications and guidance on component integration. We assume that the need for a buyer's technological expertise is higher when a component is dedicated to and customized for a buyer's specific system.

Table 2. Supplier dependence from a technological system perspective.

\begin{tabular}{|l|l|}
\hline Supplier dependence & $\begin{array}{l}\text { Supplier dependence from a } \\
\text { technological system } \\
\text { perspective }\end{array}$ \\
\hline Switching costs & $\begin{array}{l}\text { Amount of engineering needed } \\
\text { by a supplier when switching } \\
\text { buyers }\end{array}$ \\
\hline
\end{tabular}




\begin{tabular}{|l|l|}
\hline Supplier investments & $\begin{array}{l}\text { Need to adapt to a buyer's } \\
\text { system with specific } \\
\text { investments }\end{array}$ \\
\hline $\begin{array}{l}\text { Need for buyer's } \\
\text { technological expertise }\end{array}$ & $\begin{array}{l}\text { Buyer's provision of } \\
\text { technological expertise critical } \\
\text { to the supplier's component }\end{array}$ \\
\hline
\end{tabular}

Switching costs and supplier investments have partly overlapping dependencies, since, if serving a particular buyer demands specific investments, so will changing buyers. Though component engineering and supplier investments can be closely related in theory, we separate these dependencies here, since, in empirical settings, they may vary independently.

\section{Buyer-supplier relationship and technological dependencies}

4.1. Connecting technological dependency structures to purchasing categories

This chapter connect system architecture characteristics to purchasing categories in our theoretical framework. A component purchased by a buyer has a technological dependency structure that is clarified by the concepts of outbound and inbound dependence. Outbound dependence indicates the extent of components that might be affected by a change to the focal component. Inbound dependence indicates the components that might affect the focal component if they change. Hence, inbound dependence indicates the extent to which a component's design depends on other components, while outbound dependence measures the extent to which a component affects the design of other components.

Figure 2. presents a theoretical framework that connects inbound and outbound dependencies with four purchasing categories: leverage, non-critical, bottleneck, and strategic. Previous research has already connected buyer-supplier dependencies to purchasing categories [13][21], and we follow this work by naming the categories similarly. Whereas previous work has used axes of profit impact and supply risk [13], we use inbound and outbound dependence. Our theoretical framework contains three dimensions: switching costs, buyer or supplier investments, and the need for another party's technological expertise.

We argue that, when a component's inbound dependence is high, supplier customization increases. By contrast, when inbound dependence is low, a component's adaptation to the system is low, and the supplier can design its component flexibly, without strict buyer requirements. Further, if inbound dependence is low, we argue that pooling interdependencies and reciprocal interdependencies [17] are more likely to exist, since the component can more easily fit other technological systems and, thus, other supply chains. Thus, the buyer's authority over these components is less significant than in purchasing categories that lack pooling and reciprocal interdependencies. When a component's outbound dependence is high, the component significantly impacts other components. Here, a buyer must adapt its system for compatibility, which may require buyer investments and increase switching costs.

Leverage components. When a component has high inbound and low outbound dependence, it must adapt to other components. If this kind of component is outsourced, the buyer must provide a detailed description of the kind of component needed [11] to ensure system compatibility. Thus, the supplier requires the buyer's technological expertise.

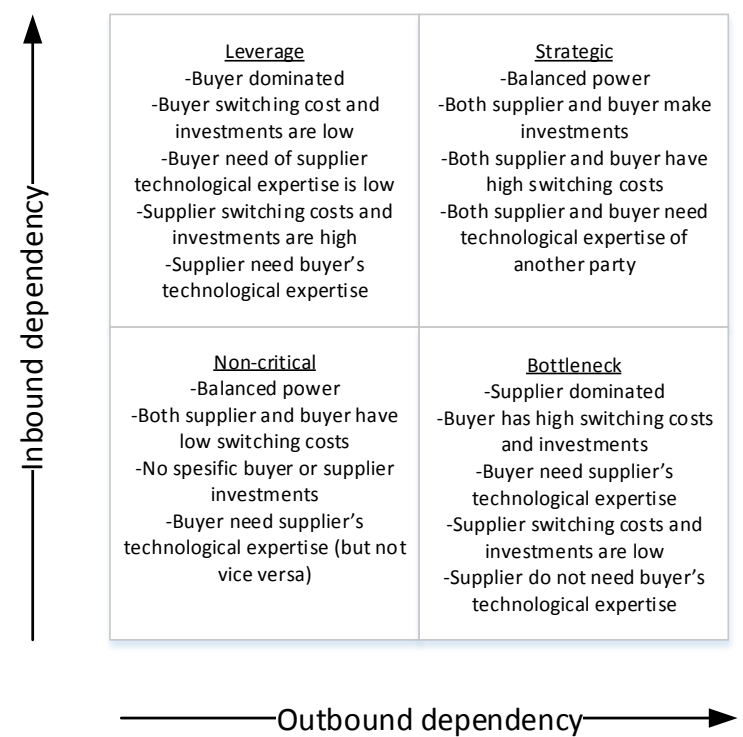

Figure 2. Theoretical framework for connecting technological dependencies of a component and a purchasing category.

Suppliers must adapt their production systems to produce these components, leading to buyer-specific investments and dependence that grow over time, especially if the investments are not transferable to other buyers. By contrast, the buyer typically does not depend heavily on the supplier's technological expertise, since the buyer provides detailed specifications of the required component.

This lower buyer dependence manifests as buyer dominance during buyer-supplier negotiations for components with high inbound and low outbound levels. Due to their low outbound level, these components do not affect other system components; thus, investment costs remain low, since the supplier can be changed and the component delivered without considerable engineering work. Switching costs, however, are considerable, since buyers must train new 
suppliers in their technological requirements. This is the main difference between the leverage category and the non-critical category. Still, this buyer dependence is not as significant as the supplier's dependence on the buyer.

Non-critical components. When a component has low outbound and inbound values, the technological dependency of the entire system is low. These components are not sources of technological dependency paths because they are independent from other components. If this kind of component is outsourced, buyers' component-system coordination costs are low, and suppliers have more freedom to design components suitable for multiple buyers. This may lead to interdependence pooling [17], in which different supply chains exploit the same component. Buyers' and suppliers' switching costs remain low, since relationship-specific investments are not necessary. Buyers can be more or less dependent on suppliers' technological expertise and/or provide more or less of their own specifications [11]. However, since inbound dependence is low, suppliers do not require buyers' specifications the way they do for leverage components. Since outbound dependence is also low, switching suppliers is not challenging for buyers. Therefore, components with low outbound dependence differ from bottleneck items in that power is balanced between buyer and supplier and overall interdependency remains low.

Bottleneck components. When a component has low inbound and high outbound values, it has a high position in the technological hierarchy. This means that other components adapt to its features, and it is not heavily influenced by changes made elsewhere in the system. If this kind of component is outsourced, the supplier is likely to have the technological expertise necessary to design the component's specifications and deliver the product [11]. Since the component has high outbound dependency, the buyer must adapt its overall system to the component; however, since inbound dependency is low, the supplier has no need to significantly adapt the component to the buyer's system. From a technological perspective, the supplier is unlikely to make buyerspecific investments. The technological system dependencies create a situation in which the adaptation of bottleneck components to other components is not technologically meaningful. These components also have pooling interdependencies [17] stemming from their low inbound dependency, since the supplier has the opportunity to leverage economies of scale in manufacturing. Reciprocal interdependencies [17] may also exist, since multiple buyers from separate supply chains may try to influence suppliers to secure component compatibility with their own systems; however, this purchasing category is likely to be dominated by the supplier.
If available suppliers provide diverse versions of the same component, buyers must choose which component to target and then adapt their systems for compatibility. Here, suppliers may have power over buyers: If other suppliers provide incompatible components that require significant buyer re-engineering, switching costs will be substantial. From a buyer's engineering perspective, switching may be challenging, since these components have long dependency paths and require extensive engineering work. However, since suppliers do not adapt to particular buyers (low inbound dependence), they face no technological constraints related to switching buyers.

Strategic components. If a component has high outbound and inbound dependencies, it has a high position in the technological hierarchy. Still, there are other components that influence the emergence of system changes. These components adapt to the system, and, simultaneously, the system adapts to them. Suppliers cannot easily switch to other buyers due to the specific investments required by their high inbound dependency; that is, suppliers must do engineering work to adapt their components to buyers' systems, thus raising switching costs.

However, buyers also face high investments, switching costs, and engineering costs caused by high outbound dependence. Both buyer and supplier are likely to need the other's technological expertise: Suppliers need buyers' component specifications to ensure compatibility, and buyers need suppliers' design and/or manufacturing expertise [11].

Strategic components are critical because their high outbound and inbound values make them specific to certain system configurations. Compatibility with other configurations is limited. Supplier and buyer are likely to mutually agree on a component design dedicated to the buyer's system. The supplier has no alternative buyers for the strategic component, and the buyer has no alternative suppliers (at least not without substantial costs). Thus, a component with high outbound and inbound levels, is likely to create a buyer-supplier power balance, since the partners' high interdependencies limit opportunities for switching.

\subsection{Measuring direct and indirect technological dependencies}

In this chapter, we define metrics for outbound and inbound dependencies. Direct technological system dependencies can be measured using the Design Structure Matrix (DSM), which maps the dependencies of each component. This captures the degree to which a change in any single element directly changes other elements. Although DSMs have significant practical implications for engineers, these presentations of direct dependencies are not sufficient indicators of system 
architecture per se [30]. The system can only be accurately described if (as in this paper) indirect dependencies are added to the analysis. Both the number of direct dependencies per component and the way the dependencies are distributed across the system are important. The literature provides instructions for both to build DSMs and measure indirect dependencies [2].

Recent literature has successfully used DSM-based metrics to comprehensively capture system dependencies [2][5][30]. Visibility matrix $V$ derives inbound and outbound dependency measures. Visibility matrix also reveals indirect dependencies. DSMs for direct dependencies are raised to successive powers, and the results show the direct and indirect dependencies of successive path lengths. These results are summed, and all positive values are set to one. Visibility matrix can be represented mathematically as follows:

$$
V=\sum M^{n}
$$

in which $\mathrm{M}$ is the DSM of direct dependencies and $\mathrm{n}=$ $[0, \mathrm{f}]$, where $\mathrm{f}$ is the longest path in the system. To calculate $\mathrm{V}$, one can use matrix multiplication or algorithms like Warshall's algorithm. From visibility matrix, two metrics are derived. These describe both a component's potential dependencies and how these dependencies relate to the overall system.

Visibility matrix produces row and column sums for each component. We call these metrics of inbound dependence (same as visibility fan-in) and outbound dependence (same as visibility fan-out), respectively [2], and leverage them in our theory development and our illustrative example. A component's inbound dependence measure is the sum of all non-zero cells in that component's column in the visibility matrix. The inbound dependence measure captures the components whose changes might affect the focal component. A component's outbound dependence is the sum of all non-zero cells in that component's row of V. Outbound dependence indicates the components that might be affected by changes to the focal component.

\subsection{Illustrative example: Turbo generator}

We provide an example of a turbo generator to illustrate inbound and outbound dependencies and the application of our framework within a real-world technological system. The example comes from an engineer with wide knowledge of turbo generators. The use of a single, explorative example seems appropriate since it adds to our concrete understanding of dependencies and system structures. Figure 3. shows the components (nodes) of a turbo generator and all possible direct and indirect dependencies (edges) among them. Thus, Figure 3. visualizes visibility matrix, and the edges form dependency paths that span the entire system. These paths are like chains through which changes to the system structure flow. Components like the rotor, turbine stator 1 , and turbine stator 2 can be seen as sources of edges; these are located upstream, and their outbound dependencies are high. Changing one of these components may change the components to which it points. For example, changing the rotor may change turbine stator 1 and turbine stator 2, as well as the components to which they point. By contrast, components like the bed and frame are located downstream; these have high levels of inbound dependency, are "targets" or ending points of multiple paths, and are likely to adapt to the changes in other components. These extremes exist because of the component hierarchy.

Figure 3. illustrates the component hierarchy by highlighting these dependency paths. It also shows where cyclic groups of the system are located. The end ring, the core material (shaft), and the squirrel cage form one cyclic group, while the rotor, stator 1 , and stator 2 form another cyclic group. These two cyclic groups are highly connected and are not equal in the component hierarchy. The turbine rotor, stator 1 , and stator 2 are more likely to define the kind of end ring, core material (shaft), and squirrel cage than vice versa. Changes in these in-cycle components will cause changes elsewhere in the system until all changes and iterations are completed [5]. On the other hand, it is unlikely for a component with low inbound and outbound dependency to be a cyclic component. To clarify Figure 3., inbound and outbound dependency values are provided in Figure 4. For clarity and legibility, Figure 4. does not list all components.

Non-critical components in this system include the feed water pump and the bearings shield. Their outbound and inbound dependencies are quite low, implying that neither buyer nor supplier is technologically locked-in to the other. There are likely several feed water pumps and bearing shields that could easily be adjusted to this system, thus increasing the availability of suppliers from the buyer's perspective.

Leverage components in the turbo generator include the frame and the bed. These components have high inbound dependencies and, thus, require extensive adaptation to system requirements. When the buyer assembles the overall system, the supplier must follow the buyer's technological specifications for these parts, resulting in buyer-specific investments for the supplier and increasing the supplier's dependence.

Buyer purchases of components like the rotor, stator 1, and stator 2 could create a supplier-dominated situation. These components have high outbound dependencies and low inbound dependencies. They occupy high positions in the component hierarchy, so other components adapt to them (not vice versa). Thus, the supplier has no technological incentive to make 


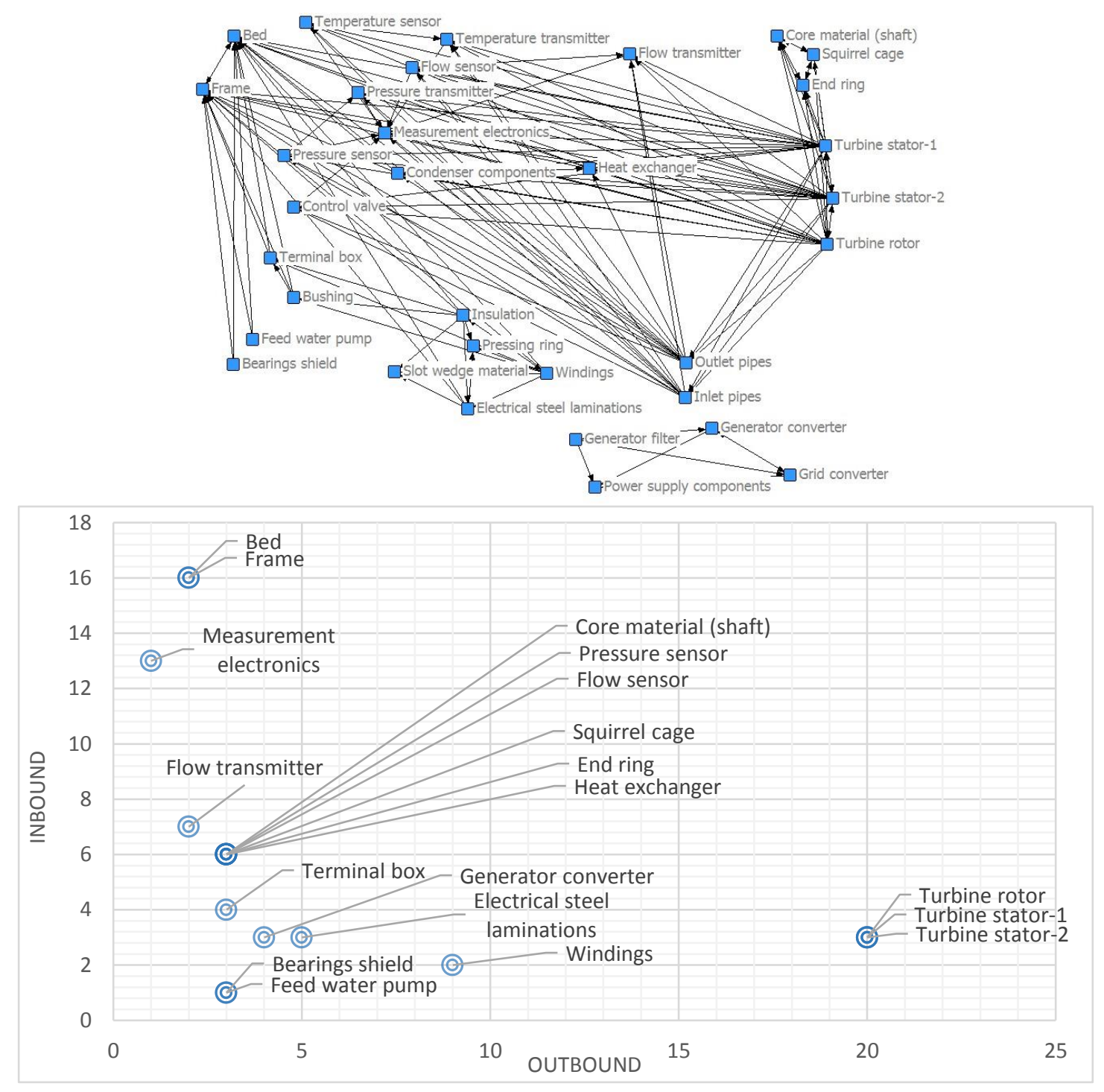

Figure 3.-4. Inbound and outbound component dependencies.

compatibility changes for a certain buyer. Rather, compatibility is the buyer's responsibility, potentially requiring buyer-side investments and increasing the buyer's dependence on the supplier. We argue that if a buyer outsources bottleneck items, the supplier is likely to have significant technological expertise in these items.

When one is studying systems empirically, not all system components will demonstrate all possible purchasing categories. In this illustrative example, purely strategic components with high outbound and inbound dependencies do not exist; thus, no concrete example of a strategic turbo generator component is provided, and only examples of bottleneck, critical, and leverage components are shown.

\section{Discussion}

In this conceptual paper we have developed a framework that connects component's technological dependencies and its purchasing category. Component dependencies at the system level are presented as inbound and outbound dependencies. Technological dependencies are connected to switching costs, relationship-specific investments, and the need for another party's technological expertise. In turn, these three factors show in which purchasing category component belong to, according to literature. In this paper the buyer is seen as the system owner and integrator, who assemble the system entity. This paper makes several contributions to the literatures on 
strategic purchasing. First, we propose metrics of inbound and outbound dependence to assess switching costs, investments, and the need for technological expertise in buyer-supplier relationships. The most important contribution is a theoretical framework in which technological dependencies determine components' purchasing categories. The division of components into purchasing categories has historically been problematic because theory provides no prescriptions or procedures for accurate measurement. Purchasing category dimensions rely on nebulous, subjective concepts, such as supply risk or profit impact, instead of operationalized measures [9] [10] even if purchasing strategies are developed according to categories. As implication of our theoretical contribution, the way how components are divided to purchasing categories can be done more objectively.

Technological dependencies form a continuum, allowing the detection of locations between purchasing categories. Technological dependencies are relatively easy to measure; thus, our framework (unlike existing subjective frameworks) can be validated and utilized by researchers and practitioners alike. Our framework does not propose that previous measures of supply risk and profit impact are incorrect. We speculate that if a leverage component with high inbound dependencies is customized to a buyer, its profit impact could be higher than that of a non-customized (non-critical) component. If a buyer would adapt its system to a bottleneck component with high outbound dependence, it cannot easily switch suppliers, increasing perceived supply risk. Strategic component (with high outbound and inbound dependence) is adapting to other components that are higher or same level in technical hierarchy which may increase its profit impact. Simultaneously there are other components that are lower in hierarchy than strategic component, and those components must adapt to strategic component which increases supply risk. The buyer may perceive simultaneously high profit impact and supply risk of strategic component.

The literature shows that the buyer firm can move a component's purchasing portfolio category [21]. Our theoretical framework does not support category changes in cases of identical architecture. The technological dependencies remain in the system, regardless of the buying firm's actions. Thus, one could question whether a buying firm can move its components and suppliers to another purchasing category simply by changing its strategy (and not its system architecture); however, industry-wide standards could enable such movements. The category movement discussion could benefit from the inclusion of the system architecture viewpoint.

Knowledge of technological dependencies is crucial for managers, since these affect relationship characteristics like switching costs, investments, needs for technological expertise, and purchasing strategy selection. As practical implication, our research illustrates what kind of situations technological dependencies create. Our theoretical framework could bridge engineers and business managers, since engineering decisions regarding system structure interact with buyer-supplier relationship characteristics. Though our theory takes the system's technological structure as a given, design choices should be made with input from the purchasing perspective [18].

This research has its limitations. We assume that buyers are the assemblers and integrators of systems with (potentially) multiple suppliers. Otherwise, our theoretical framework is not applicable. Outbound and inbound dependence require a technological system context; if system integration is not the buyer's responsibility, this falls to another supply chain actor. In such a case, the buyer-supplier relationship is defined by factors other than inbound and outbound dependence. Second, if all system components have the same inbound and outbound dependencies (e.g. in systems with highly connected components; see [42]), our operationalization does not apply. Third, we assume that separate components have separate supplier relationships. In reality, one supplier can provide multiple parts, and relationships develop separately from individual components. We preserve the component-supplier linkage, since we do explore the dimensions of buyer-supplier relationships not linked to technology. Fourth, our theoretical framework does not consider dominant industry designs or mass supplier customizations. Dominant designs set industry specifications and reduce compatibility issues, thus changing the relationship dependence described in our framework. Similarly, mass customization can change a supplier's dependence of a buyer by lowering the manufacturing costs of customized components [24]. Our theoretical framework should be tested empirically in future research (e.g. in the context of turbo generators), and the impacts of dominant designs and mass customization should be considered.

\section{Conclusion}

This paper has developed a theoretical framework to explain how systems' indirect and direct technological dependencies (inbound and outbound dependence) impact on buyers' and suppliers' switching costs, investments, needs for technological expertise and, ultimately, component purchasing categories. Previous research has divided components into purchasing categories without considering prevailing technological dependency. We extend the strategic purchasing literature by identifying how components' technological dependencies relate to their purchasing categories. We 
believe that these considerations of technological dependencies are fruitful for purchasing research.

\section{References}

[1] J. Pfeffer and G. R. Salancik., The external control of organizations: A resource dependence perspective. Stanford University Press, 2003.

[2] C. Baldwin, A. MacCormack, and J. Rusnak, "Hidden structure: Using network methods to map system architecture," Res. Policy, vol. 43, no. 8, pp. 1381-1397, Oct. 2014.

[3] A. Cabigiosu, F. Zirpoli, and A. Camuffo, "Modularity, interfaces definition and the integration of external sources of innovation in the automotive industry," Res. Policy, vol. 42, no. 3, pp. 662-675, 2013.

[4] F. Zirpoli and A. Camuffo, "Product architecture, inter-firm vertical coordination and knowledge partitioning in the auto industry," Eur. Manag. Rev., vol. 6, no. 4, pp. 250-264, 2009.

[5] M. E. Sosa, J. Mihm, and T. R. Browning, "Linking Cyclicality and Product Quality.," Manuf. Serv. Oper. Manag., vol. 15, no. 3, pp. 473-491, 2013.

[6] P. Kraljic, "Purchasing must become supply management," Harv. Bus. Rev., vol. 61, no. 5, pp. 109-117, 1983.

[7] D. Luzzini and F. Caniato, "A transaction costs approach to purchasing portfolio management," ... Prod. Manag., vol. 32, no. 9, pp. 1015-1042, 2012.

[8] S. S. Padhi, S. M. Wagner, and V. Aggarwal, "Positioning of commodities using the Kraljic Portfolio Matrix," J. Purch. Supply Manag., vol. 18, no. 1, pp. 1-8, 2012.

[9] R. F. Olsen and L. M. Ellram, "A portfolio approach to supplier relationships," Ind. Mark. Manag., vol. 26, no. 2, pp. 101-113, 1997.

[10] J. Ramsay, "Power measurement," Eur. J. Purch. Supply Manag., vol. 2, no. 2, pp. 129-143, 1996.

[11] R. Nellore and K. Söderquist, "Portfolio approaches to procurement," Long Range Plann., vol. 33, no. 2, pp. 245-267, 2000.

[12] M. Bensaou, "Portfolios of buyer-supplier relationships," Sloan Manag. Rev. VO - 40, no. 4, p. 35, 1999.

[13] M. C. J. Caniëls and C. J. Gelderman, "Power and interdependence in buyer supplier relationships: A purchasing portfolio approach," Ind. Mark. Manag., vol. 36, no. 2, pp. 219-229, 2007.

[14] M. C. J. Caniëls and C. J. Gelderman, "Purchasing strategies in the Kraljic matrix - A power and dependence perspective," J. Purch. Supply Manag., vol. 11, no. 2-3, pp. 141-155, 2005.

[15] J. Pfeffer, "A resource dependence perspective on interorganizational relations," in Intercorporate relations: The structural analysis of business, M. S. Mizruchi and M. Schwartz, Eds. Cambridge, UK: Cambridge University Press, 1987, pp. 22-55.

[16] G. Spina, F. Caniato, D. Luzzini, and S. Ronchi, "Assessing the use of External Grand Theories in Purchasing and Supply Management research," $J$.
Purch. Supply Manag., vol. 22, no. 1, pp. 18-30, 2016.

[17] A. Dubois, K. Hulthén, and A. C. Pedersen, "Supply chains and interdependence: A theoretical analysis," J. Purch. Supply Manag., vol. 10, no. 1, pp. 3-9, 2004.

[18] M. Persson, M. J. Eklind, and M. Winroth, "Coordinating External Manufacturing of Product Modules," vol. in press, pp. 1-25, 2015.

[19] C. J. Gelderman and A. J. Van Weele, "Handling measurement issues and strategic directions in Kraljic's purchasing portfolio model," J. Purch. Supply Manag., vol. 9, no. 5-6, pp. 207-216, 2003.

[20] M. Pagell, Z. Wu, and M. E. Wasserman, "Thinking differently about purchasing portfolios: An assessment of sustainable sourcing," J. Supply Chain Manag., vol. 46, no. 1, pp. 57-73, 2010.

[21] M. Dabhilkar, L. Bengtsson, and N. Lakemond, "Sustainable supply management as a purchasing capability: A power and dependence perspective," Int J Oper. Prod. Manag., vol. 36, no. 1, pp. 2-22, 2016.

[22] K. Ulrich, "The role of product architecture in the manufacturing firm," Res. Policy, vol. 24, no. 3, pp. 419-440, May 1995.

[23] R. Sanchez and J. T. Mahoney, "Modularity, Flexibility, and Knowledge Management in Product and Organization Design.," Strateg. Manag. J., vol. 17, pp. 63-76, 1996.

[24] Q. Tu, M. A. Vonderembse, and B. Ragu-Nathan, "The impact of time-based manufacturing practices on mass customisation and value to customer," $J$. Oper. Manag., vol. 19, pp. 201-217, 2001.

[25] J. P. Murmann and K. Frenken, "Toward a systematic framework for research on dominant designs, technological innovations, and industrial change," Res. Policy, vol. 35, no. 7, pp. 925-952, 2006.

[26] S. K. Fixson and J. K. Park, "The power of integrality: Linkages between product architecture, innovation, and industry structure," Res. Policy, vol. 37, no. 8, pp. 1296-1316, 2008.

[27] M. E. Sosa, S. D. Eppinger, and C. M. Rowles, "The Misalignment of Product Architecture and Organizational Structure in Complex Product Development," Manage. Sci., vol. 50, no. 12, pp. 1674-1689, 2004.

[28] D. Pick and M. Eisend, "Buyers' perceived switching costs and switching: A meta-analytic assessment of their antecedents," J. Acad. Mark. Sci., vol. 42, no. 2, pp. 186-204, 2014.

[29] G. Dosi, "Technological paradigms and technological trajectories: a suggested interpretation of the determinants and directions of technical change," Res. Policy, vol. 11, no. 3, pp. 147-162, 1982.

[30] A. MacCormack, J. Rusnak, and C. Y. Baldwin, "Exploring the Structure of Complex Software Designs: An Empirical Study of Open Source and Proprietary Code," Manage. Sci., vol. 52, no. 7, pp. 1015-1030, 2006. 